
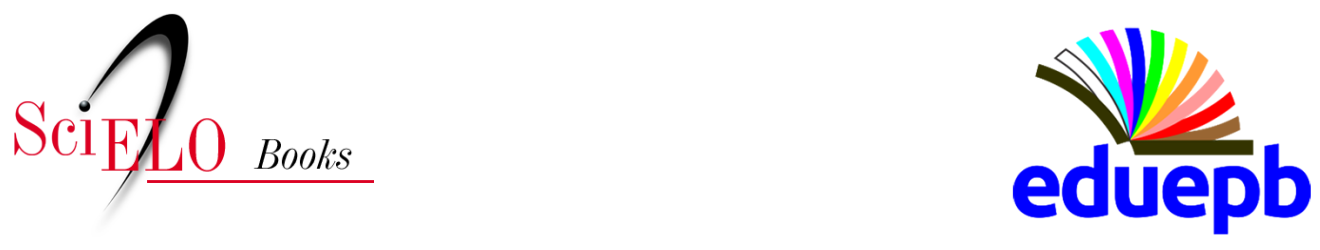

\title{
Influências e Legados \\ Manelito Vilar - Celso Furtado, a Sudene e o Semiárido: enfrentando a seca social
}

\author{
Andreza Dantas Albuquerque \\ Walter Wasconcelos
}

\section{SciELO Books / SciELO Livros / SciELO Libros}

ALBUQUERQUE, A. D., and WASCONCELOS, W. Manelito Vilar - Celso Furtado, a Sudene e o Semiárido: enfrentando a seca social. Interviewed: Manelito Vilar. In: SOUSA, C. M., THEIS, I. M., and BARBOSA, J. L. A., eds. Celso Furtado: a esperança militante (Depoimentos): vol. 2 [online]. Campina Grande: EDUEPB, 2020, pp. 239-246. Projeto editorial 100 anos de Celso Furtado collection. ISBN: 978-65-86221-11-4. https://doi.org/10.7476/9786586221671.0010.

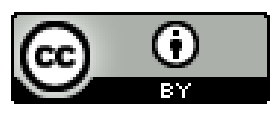

All the contents of this work, except where otherwise noted, is licensed under a Creative Commons Attribution 4.0 International license.

Todo o conteúdo deste trabalho, exceto quando houver ressalva, é publicado sob a licença Creative Commons Atribição 4.0.

Todo el contenido de esta obra, excepto donde se indique lo contrario, está bajo licencia de la licencia Creative Commons Reconocimento 4.0. 


\section{Manelito Vilar}

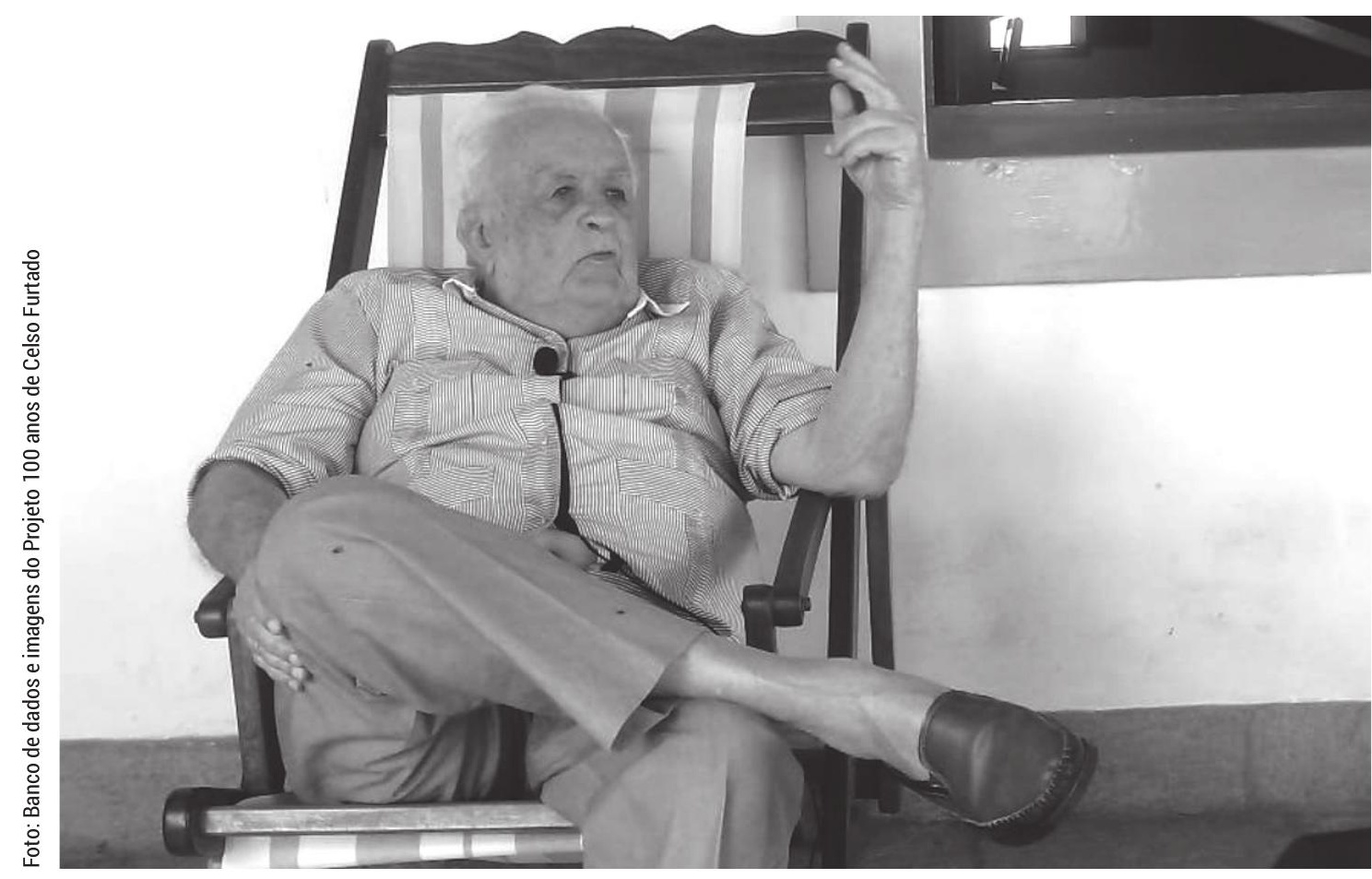

4

Em primeiro lugar, eu não sou contra a seca. Tem que estabelecer uma estratégia de convivência com ela. A água que Deus manda já é suficiente para armar os projetos de desenvolvimento. No global, a base mudou a partir da Sudene, a partir da leitura do Dr. Celso Furtado... Isso aí a Sudene virou de cabeça para baixo. Agora, precisa passar um tempo. Uma sucessão de gerações operando nesse patamar para consolidar 0 caminho definitivo do Nordeste 


\title{
Celso Furtado, a Sudene e o Semiárido: enfrentando a seca social
}

Andreza Dantas Albuquerque1

Walter Wasconcelos2

\begin{abstract}
A os 83 anos, Manoel Dantas Vilar Filho, o Manelito, como prefere ser chamado, nos recebeu em sua casa, na Fazenda Carnaúba, em Taperoá (PB), onde vive desde 1971, quando retornou a morar na Paraíba, e de onde saiu aos 11 anos para estudar no Recife, capital do Estado de Pernambuco. Formado em Engenharia Civil pela Universidade Federal de Pernambuco (UFPE), trabalhou no Departamento Nacional de Obras Contra as Secas (DNOCS) e na Sudene, foi professor da UFPE, compôs o grupo para instituição da Companhia de Água e Esgoto da Paraíba (CAGEPA), sendo seu último cargo público a direção do Instituto Nacional do Semiárido (INSA), em 2005.

A face mais conhecida de Manelito é a do criador. Desde seu retorno a Taperoá, na década de 1970, passou a dedicar-se à pecuária e à criação de caprinos e ovinos, com raças nativas e adaptadas ao Semiárido Nordestino. A sabedoria e a teimosia de seu proprietário fazem da Fazenda Carnaúba um exemplo de convivência com o Semiárido.

Manelito aceitou o convite do Projeto Editorial 1oo anos Celso Furtado para uma conversa sobre sua experiência na Sudene e da sua proposta de fazer da gestão do INSA um legado para a reversão de uma leitura caricatural e negativa do Nordeste, inspirada na proposta de desenvolvimento de Furtado. Assim, a entrevista aqui apresentada foi mediada
\end{abstract}

1 Jornalista, Doutora em Ciência, Tecnologia e Sociedade pala UFSCar, pesquisadora vinculada ao Programa de Pós-graduação em Desenvolvimento Regional da Universidade Estadual da Paraíba na condição de estágio pós-doutorado.

2 Graduado Engenheiro Agrônomo pelo Centro de Ciências Agrárias-Campus II da Universidade Federal da Paraíba (UFPB, 2005), Especialista em Agroecologia pelo Centro de Formação de Tecnólogos Campus III da UFPB (2008), Mestre em Zootecnia na área de Forragicultura pelo Programa de Pós-Graduação em Zootecnia do Centro de Ciências Agrárias - Campus II da UFPB (2011). 
pelos seguintes temas: Reminiscências dos primeiros contatos do entrevistado com Furtado; Relação acadêmica e técnica de Manelito com Furtado; Leitura do entrevistado quanto ao legado Furtadiano; Pertinência das proposições de Furtado para os desafios dos tempos atuais; $\mathrm{O}$ entrevistado, Furtado e o desenvolvimento regional.

O ano de 1959 é um marco para o Nordeste. Diante do descontentamento com as ações do Governo Federal para a região, surge no cenário político o economista nordestino, Celso Furtado, com a missão, o comprometimento e o apoio do presidente Juscelino Kubitscheck, de propor uma política de desenvolvimento econômico para o Nordeste.

Naquele ano, Manelito estava cursando o último ano de Engenharia Civil na UFPE quando se começou a discutir a criação da Sudene. "De mente acessa e atento ao que estavam discutindo" o aspirante a engenheiro articulou uma palestra com o Dr. Celso Furtado na Escola de Engenharia, do Recife. Na ocasião, Furtado explanou sobre o grupo de trabalho que vinha se dedicando a um estudo sistemático sobre as doze frentes de ação para o Nordeste. Naquele primeiro encontro, foi a leitura da seca apresentada por Celso Furtado o que mais despertou o interesse do jovem Manelito. E o que dizia Furtado: o problema da zona semiárida do Nordeste não era a falta de chuva e sim a existência de uma economia inadequada ao meio e extremamente vulnerável ao período de seca. "Essa teoria e essa exposição do Dr. Celso de abordagem da seca, essencialmente, era a mesma coisa do meu pai nos meus ouvidos", destaca Manelito.

A lei de criação da Sudene foi enviada ao Congresso em fevereiro de 1959, mas só foi aprovada em dezembro, com a posse de Furtado vindo a ocorrer em Janeiro de 1960. Manelito recorda os bastidores dessa espera:

"A aprovação da lei de criação da Sudene no Parlamento estava sendo sabotada pela bancada do Ceará, porque estava previsto que a Sudene seria no Recife, e os cearenses queriam carregar para Fortaleza. Resumindo, era isso. Resultado, terminei o curso, me formei, e nada 
da Sudene. Aí eu fui embora, menino, bem novinho, fui para Brasília, antes da inauguração. E ficou um colega meu, que tinha mais de meio sangue de doido, encarregado de me avisar da evolução real, da Sudene no Nordeste. Ele, inclusive, me telegrafou para eu voltar, antes de acontecer isso. Aí ele me avisou antes de a Sudene ser consolidada, aí eu vim e fui trabalhar no DNOCS. Passei oito meses em Serra Talhada na residência do DNOCS. Era uma vaga no Recife e outra em Serra Talhada. Aí fui embora para o Sertão de Pernambuco, nas terras dos Ferreiras, os primos de Lampião".

O tempo no DNOCS só fazia aumentar a afinidade de Manelito com a proposta da Sudene. "Quando eu era estudante de Engenharia o DNOCS tinha tudo o que um engenheiro pretendesse. Fazia estrada, construção civil, mas a primeira coisa que peguei na vida foi com o nome: Departamento Nacional de Obras Contra a Seca. Será que o Hemisfério Norte só encontrou o caminho de produzir e prosperar depois do 'Departamento Nacional de Obras Contra a Neve?' É engraçado. Aí eu dizia: O que é que era a favor?".

O DNOCS é o órgão federal mais antigo em atuação no Nordeste, criado em 1909 sob o nome de Inspetoria de Obras Contra as Secas. Comandado por engenheiros, entre a década de 1940 e 1960 atuava em dois grupos, um voltado a produção de estudos de hidrologia, pluviometria e águas subterrâneas no Semiárido; e outro grupo que estava interessado em resolver os problemas da seca de maneira prática, comandando, assim, as políticas de açudagem e organizando as frentes de trabalho. Essa era a política do governo federal para o Nordeste, principalmente nos períodos de estiagem.

"Meu pai fazia um açude por fazenda. Eram três, essa e mais duas. Para resolver o problema de água para beber, né? Porque açude era antieconômico. Aí de repente toma três anos de seca seguidos, seca tudo de uma vez. Então, metade da água de um açude se perde por evaporação. É a forma mais antieconômica, menos eficaz de resolver problema de abastecimento d'água". Recorda-se.

Manelito nos conta que durante os oito meses de espera pela abertura da Sudene ficou atento a tudo que era publicado por Furtado para saber com quem estaria tratando: "quando a Sudene abriu, contratou uma leva de quatro técnicos. Eu era um deles. Porque eu estava lá na porta. Você há de convir, a expectativa criada com a criação da Sudene, entende? Furtado reverteu a filosofia da água, revogou uma leitura secular da seca, baseado em água, né? A seca do Nordeste, é muito mais 
uma crise na oferta de alimento na região do que na oferta de água. Expandir a fronteira agrícola da região até a Amazônia maranhense, para garantir o abastecimento do gênero básico. E adaptar a agricultura da zona seca, à seca. Significa a pecuária, como era desde a manjedoura de Belém. A atividade predominante na Zona Seca é a pecuária. Então aqui no Nordeste você faz uma leitura equivocada de zoo anos, de irrigar. Produzir no Nordeste, só com
Eu lembro que havia uma pressão enorme em cima da Sudene, para definir uma política de açudagem. A leitura hidraulicista da seca. Aí Furtado disse: 'A Sudene só vai definir uma política de açudagem para o Nordeste quando estiver definida a política de águas'. irrigação. Faz 300 anos, e não acharam a água ainda", ressalta Manelito.

A proposta da Sudene para a região Nordeste confrontava com o pensamento das autoridades locais, que temiam as mudanças proposta por Furtado e o corpo técnico da Superintendência. A ideologia dos grupos dominantes era que a culpa para o atraso da região estava no clima; já para Furtado, a verdadeira crise era provocada pela seca era social.

A seca era a razão de ser do DNOCS, assim o atrito entre o órgão e Furtado foi inevitável. Sobre essa questão Manelito recorda a pressão sob Furtado para uma definição de como a Superintendência iria atuar com relação a política de açudagem que era empregada pelo DNOCS e apoiada pelos governadores da região. "Eu lembro que havia uma pressão enorme em cima da Sudene, para definir uma política de açudagem. A leitura hidraulicista da seca. Aí Furtado disse: A Sudene só vai definir uma política de açudagem para o Nordeste quando estiver definida a política de águas".

Para Furtado, a seca tinha se transformado em uma indústria, e, compreendendo isso, a proposta da Sudene tinha como objetivo utilizar de forma mais justa as áreas a serem irrigadas com dinheiro federal. Isso estava previsto na Lei de Irrigação proposta em 1959 e que não chegou a ser aprovada pelo Congresso, por não ter apoio dos políticos nordestinos.

Como nos conta Manelito: "O governador do Ceará, Parsifal Barroso, danado da vida porque a Sudene não definia a posição de açude. Repare que uma das primeiras coisas que a Superintendência fez foi criar a CONESP, Companhia Nordestina de Sondagens e Perfurações, para furar poço por todo canto. A maioria é salobra, então tinha outra coisa, dessalinizador. Ou seja a teoria Celso Furtado colocou de cabeça para baixo, de 
abordagem ao Semiárido, em relação ao DNOCS. Eu achei muita graça", diverte-se ao relembrar os fatos.

Na Sudene, Manelito atuou na área de Saneamento e Abastecimento D'água, desde sua criação até o golpe de 1964. Desta fase o agropecuarista recorda que o setor que ele trabalhava foi fechado pouco antes do golpe, assim: "Eu não fui expelido, não, porque eu já tinha saído. Eu estava no Sertão, fazia parte, mas na área de Saneamento e Abastecimento $D$ 'água que tinha sido fechado por um general doido, do Quarto Exército, na Sudene". Sobre o Furtado superintendente, Manelito o descreve como sendo um gestor bem articulado, afinado. "Perguntava a três, quatro pessoas, mas era ele quem resolvia tudo. E é aí que está a grande virtude. Todos os documentos da Sudene eram escrito por ele. Era bem afinado. Tudo era de uma forma articulada. Partia daqui para chegar no chão. Isso eu tentei fazer lá no instituto (INSA) e consegui", enfatiza.

Manelito teve uma carreira bem sucedida como Engenheiro, após seu período na Sudene, exerceu a função de Professor na Universidade Federal de Pernambuco, mas a morte de seu pai o fez retornar à Fazenda Carnaúba, em 1971, para dar continuidade às atividades agropecuárias que eram desenvolvidas por seu Manoel Vilar, falecido em 1969.

A Fazenda Carnaúba, administrada por Manelito e seus filhos Inês e Daniel, é um exemplo de como é possível conviver com a semiaridez da região e viver economicamente no Semiárido sem travar uma guerra contra a escassez de chuva ou as características do solo. O caminho da pecuária apropriada por Manelito se distingue no cenário nordestino por resgatar e valorizar a rusticidade das cabras "nativas" adaptadas a sobreviver no ambiente seco, mas de vegetação rica e de grande potencial para a pecuária de forma sustentável.

A forma de conduzir a pecuária na Carnaúba foi fortemente inspirada na matriz do pensamento de Celso Furtado para a região, pois para Manelito "a exposição de Dr. Celso era igual à conversa de meu pai, nos ouvidos da gente". A experiência de vida de Manelito como engenheiro, professor, agropecuarista e, principalmente, como estudioso do Semiárido, o levou ao comando do Instituto Nacional do Semiárido, que durante sua criação homenageava Celso Furtado.

O INSA, que recebeu o nome de Celso Furtado, foi criado em 2004 como órgão vinculado ao Ministério da Ciência e Tecnologia. Manelito foi convocado a dar forma ao Instituto e viu no convite a oportunidade de devolver ao Nordeste o protagonismo de seu desenvolvimento. Assim, ao mesmo tempo em que a proposta do INSA se fundamentava 
nas bases da antiga Sudene, lançava as bases tecnológicas para a reversão de uma leitura caricatural e negativa do Nordeste.

O Instituto foi pensado para atuar como núcleo de pesquisa consistente sobre as lavouras xerófilas; centro de pecuária de múltipla função do Nordeste, para pesquisa complementar e difusão regional de genética apropriada e educação pública saudável sobre o Semiárido. Sobre a criação do INSA-CF Manelito ressalta que a sua primeira batalha foi trazer a sede da Instituição para a zona seca da região semiárida. "Eu disse a Dr. Arraes (Miguel Arraes, então Deputado Federal de Pernambuco): 'Chega de botar as instituições do Semiárido à beira d'água'. O SEPASA, que era o Serviço do Semiárido da Embrapa, estava previsto para ser em Campina Grande, na redação dos documentos iniciais. Foram botar na beira d'água do São Francisco, em Petrolina. Quando eu assumi o INSA fui enfático: 'então trate de botar numa terra, na zona seca de Campina Grande. Eu quero que tenha o mínimo de água'. Uma manobra do Dr. Arraes sediou em Campina Grande, tirou da beira d'água, isso foi conflito meu, mas não tinha nem orçamento, nem quadro de pessoal. Para você ter uma ideia, que eu não imaginava nunca, eu me rendi a ele (Arraes), e a Cássio, para arrumar a fazenda. 'Sede dele dentro de uma sala? Estou fora!"”.

Manelito ficou na direção do INSA até a seleção do primeiro diretor do Instituto em 2007. Seu trabalho a frente do Instituto teve o reconhecimento do então superintendente da ADENE, José Zenóbio Teixeira de Vasconcelos, órgão que antecedeu a atual Sudene: "Outro dia eu vinha numa avião de Fortaleza para Recife, e o superintendente da ADENE, que foi a instituição intermediária entre a Sudene e a nova Sudene. Dentro do avião, ele observando minha roupa, minha farda (fazendo referência ao conjunto de calça e blusa azul, seu traje de todas as ocasiões), ele sentou junto de mim, aí ele disse: 'É Manelito, eu vejo. Eu estou acompanhando, com muita atenção, o que você está fazendo, e escrevendo e dizendo. Nesses termos, o INSA é o embrião da nova Sudene, nos termos em que você está colocando, é o embrião da verdadeira Sudene”, relata com orgulho.

Perguntamos a Manelito sua percepção sobre as questões atuais do Nordeste, o que é que permanece sem solução na região, no sentido de pensar o Semiárido? Avançou em alguma coisa? "Avançou a partir da Sudene. A leitura 'hidraulicista' da seca arrefeceu. Ainda hoje, está gravado no meu celular, o pessoal de uma dessas instituições de TV perguntou: 'O senhor é um visionário?' Em primeiro lugar, eu não sou contra 
a seca. Tem que estabelecer uma estratégia de convivência com ela. A água que Deus manda já é suficiente para armar os projetos de desenvolvimento. No global, a base mudou a partir da Sudene, a partir da leitura do Dr. Celso Furtado. A irrigação artificial deixou de ser o procedimento excludente para produzir no Nordeste. Isso aí a Sudene virou de cabeça para baixo. Agora, precisa passar um tempo. Uma sucessão de gerações operando nesse patamar para consolidar o caminho definitivo do Nordeste. Veja, a lavoura irrigada era excludente. Isso acabou. Pecuária era o caminho. Eu tive muito a ver com isso na Sudene. Agora, eu quero ficar quieto em casa. Nem que sejam pessoas simpáticas, como vocês, para fazer isso, eu não quero".

Então, todo aquele diagnóstico de Furtado ainda é válido para o Nordeste de hoje, perguntamos: "Vale demais! Eu me lembro, inclusive, das quatro perguntas do tal comitê de busca (Referência ao processo de seleção do diretor do INSA), armado no Ministério da Ciência e Tecnologia em Brasília. Eu pedi que acrescentasse mais uma questão: o que é que os candidatos a diretor acham dos Planos Diretores da Sudene e se vê algum sentido para a utilidade atual que ele poderia ter. Embaralhou todo mundo".

Finalizamos com a questão: para os desafios que a gente tem, Furtado faz falta? "Já não faz tanta. Repare como eu estou dizendo. Já não faz tanta. Porque a equação teórica ele arrumou. Daí para frente...”

Nota dos editores:

A entrevista foi realizada em 19 de fevereiro de 2020, uma das últimas concedidas por Manelito Vilar, que faleceu em 28 de julho de 2020, dias após o fechamento da trilogia lançada em 26 de julho. A Manelito, nossa gratidão e respeito. 